\title{
A Romanian study on the impact of glypressin in laparoscopic myomectomy
}

\author{
DANIELA ROXANA MATASARIU ${ }^{1}$, ALEXANDRA URSACHE ${ }^{1}$, LOREDANA HIMINIUC ${ }^{1}$, BOGDAN TOMA ${ }^{1}$, \\ VASILE LUCIAN BOICULESE ${ }^{2}$, DORINA RUDISTEANU ${ }^{3}$ and IRINA DUMITRASCU ${ }^{1,3}$
}

\begin{abstract}
Departments of ${ }^{1}$ Obstetrics and Gynecology and ${ }^{2}$ Preventive Medicine and Interdisciplinarity Medical Informatics and Biostatistics, 'Grigore T. Popa' University of Medicine and Pharmacy, 700115 Iasi; ${ }^{3}$ Department of Obstetrics and Gynecology, 'Cuza Voda' Obstetrics and Gynecology Clinical Hospital, 700038 Iasi, Romania
\end{abstract}

Received February 22, 2021; Accepted March 24, 2021

DOI: $10.3892 /$ etm.2021.10387

\begin{abstract}
A major myomectomy-associated problem is excessive blood loss. The aim of the present study was to evaluate the effect of glypressin on blood loss during laparoscopic myomectomy (LM) in women with uterine myomas. A total of 188 women scheduled for LM for uterine myomas were divided into two groups. The one group of women $(n=64)$ received a 5-ml intramyometrial injection of glypressin $0.2 \mathrm{mg} / \mathrm{ml}$ (glypressin group; group 1). The other group of women $(n=124)$ (group 2) had an LM performed without any other method to reduce blood loss. The decrease in postoperative hemoglobin $(\mathrm{Hb})$, hematocrit $(\mathrm{Ht})$, morbidity and duration of hospital stay were assessed. The results revealed that $\mathrm{Hb}$ and $\mathrm{Ht}$ (as it was presumed) exhibited similar changes in our study. Statistically significant differences $(\mathrm{P}<0.05)$ were obtained between the two groups in terms of $\mathrm{Hb}$ and $\mathrm{Ht}$; after $\mathrm{LM}$ both $\mathrm{Hb}$ and $\mathrm{Ht}$ were decreased. In conclusion, the impact of glypressin administration in hemorrhage control in uterine leiomyomas may establish new future perspectives, regarding its administration in gynecological hemorrhagic pathologies.
\end{abstract}

\section{Introduction}

Myomas or fibroids are benign smooth muscle tumors of the uterus $(1,2)$. Uterine leiomyomas are the most common benign uterine tumors in women of reproductive age, with an incidence of $70 \%(3,4)$. The majority are asymptomatic, and only $30-40 \%$ of women with myomas present with symptoms (such

Correspondence to: Dr Alexandra Ursache, Department of Obstetrics and Gynecology, 'Grigore T. Popa' University of Medicine and Pharmacy, 16 University Street, 700115 Iasi, Romania E-mail: carpalecsandra@yahoo.com

Abbreviations: LM, laparoscopic myomectomy; $\mathrm{Hb}$, hemoglobin; $\mathrm{Ht}$, hematocrit; EBL estimated blood loss

Key words: glypressin, vasopressin, terlipressin, myoma, laparoscopic intramural myomectomy as heavy menstrual bleeding, infertility, recurrent pregnancy loss and pressure symptoms) (3,5). For these women the treatment remains the surgical removal of these fibroids $(1,2)$. For the women who wish to preserve their uterus, the gold standard treatment is myomectomy. Abdominal myomectomy, transvaginal myomectomy, laparoscopic myomectomy (LM), laparoscopically-assisted myomectomy via minilaparotomy incision, and robot-assisted LM are the techniques used in gynecological myomectomy practice. The recent technological advances in endoscopy have allowed gynecological surgeons to implement LM in practice $(1,6-8)$.

The major problem associated with myomectomy is the excessive bleeding from multiple uterine blood supply (9). Myomectomy is an extremely hemorrhagic intervention. Numerous measures have been assessed in an attempt to reduce blood loss during LM (10).

The more commonly used interventions are uterine artery embolization/ligation, pericervical tourniquet placement, intramyometrial vasopressin/epinephrine administration, use of uterotonics (including ergometrine, oxytocin and misoprostol), and antifibrinolytic agents (such as tranexamic acid and recombinant factor VIIa) $(2,3,11)$.

A skillful surgeon may prevent excessive operative blood loss, the results being better when combined with other techniques for reducing the hemorrhage. Vasopressin and oxytocin are usually used to prevent excessive blood loss during $\operatorname{LM}(1,12,13)$. The antidiuretic hormone vasopressin is injected intramyometrially to reduce blood loss during surgery $(1,14)$. Vasopressin is a direct vasoconstrictor that has been revealed to reduce bleeding during myomectomy. Local administration of vasopressin may cause severe or even lethal complications in spite of the rarity of its side effects (9).

Laparoscopy became popular among gynecologists and patients due to a faster recovery, shorter hospital stay, improved esthetic results, and excellent long-term results in terms of the resolution of symptoms and reproductive outcomes $(8,10,15-17)$.

Vasopressin is a synthetic antidiuretic hormone analogue. It has been approved in several countries being used as a vasoconstrictor agent in numerous surgical procedures, LM included $(10,18,19)$. Vasopressin produces a local vasoconstriction that lasts $\sim 30 \mathrm{~min}$ (10). 
Vasopressin appears to affect the blood vessels, however, the exact mechanism remains unknown. There are only a few studies regarding the interesting phenomenon of the effect of vasopressin on blood vessels.

Clinicians have followed the uterine blood flow after vasopressin administration and reported that its effect extends to the uterine artery. During laparoscopic surgery the effect of vasopressin extends to both local and general circulation (14).

In Europe, vasopressin is usually used as a vasoconstrictor during surgery, but in some of these countries vasopressin is not available, and thus, terlipressin (a synthetic long-acting vasopressin analogue) is used. In Romania, a synthetic form of vasopressin, glypressin (terlipressin acetate) $0.2 \mathrm{mg} / \mathrm{ml}$ solution is used.

The aim of the present study was to assess the efficacy and safety of intramyometrial glypressin administration in reducing blood loss during LM.

\section{Materials and methods}

Patients. An observational study was conducted at the Iasi 'Cuza Voda' University Hospital of Obstetrics and Gynecology (Romania). Our unit is a tertiary referral center for advanced laparoscopic gynecological procedures in Northeastern Romania. The present study was conducted to investigate whether the use of glypressin played an important role in LM, comparing cases in which LM was performed with the use of this agent and without the use of this or any other vasoconstrictor agent.

Data was collected from 188 patients, between 23 and 54 years old, who underwent LM at our department from January 2013 to December 2019. Of these, in 64 patients glypressin was administrated intraoperatively (group 1) and in 124 patients no vasoconstrictor was administered (group 2). All procedures were performed by senior surgeons at our department. All patients signed an informed consent, including permission to use glypressin and power morcellation to extract myomas. Ethical approval was obtained from the Ethics Committee of 'Cuza Voda' Obstetrics and Gynecology Clinical Hospital (Iasi, Romania).

Inclusion and exclusion criteria. The inclusion criteria were as follows: Myomas 50-150 mm and up to 5 fibroids, and no contraindications to the use of glypressin. The exclusion criteria were as follows: Open myomectomy, vaginal myomectomy, and the cases that required conversion to open surgery, history of bleeding diathesis, concurrent anticoagulation therapy, and endometrial or cervical malignancies.

Study groups and parameters assessed. The two study groups were compared in terms of size and number of fibroids, estimated blood loss (EBL) indirectly by using pre- and postoperative hemoglobin $(\mathrm{Hb})$ and hematocrit $(\mathrm{Ht})$ values, rates of glypressin-associated intra- and postoperative complications, and length of hospital stay.

Preoperative, operative, and postoperative data were collected from both groups in a prospective manner. The differences in the age, body weight, and number of myomas of patients were not significant.
The primary outcome measure was intraoperative blood loss during surgery, evaluated using the levels of $\mathrm{Hb}$ and $\mathrm{Ht}$ before and after the surgery, intra- and postoperative morbidity, and duration of hospital stay.

In cases treated with glypressin, a solution of $0.2 \mathrm{mg} / \mathrm{ml}$ $(5 \mathrm{ml})$ was injected into the myometrium and the subcapsular space around the myoma in all patients. In the patients with multiple tumors the injection was repeated before the enucleation of each myoma. The myometrial defect was sutured using 2-0 V-LOC (Covidien; Medtronic Limited), barbed-delayed absorbable sutures.

The mean pulse rate, blood pressure, electrocardiogram, and temperature (hourly) of patients were monitored intraoperatively and exhibited no significant changes. $\mathrm{Hb}$ and $\mathrm{Ht}$ levels were recorded the day after surgery (postoperative day 1) and compared with preoperative levels. The need for blood transfusion, blood pressure, pulse, and temperature as well as the duration of hospital stay were also recorded.

Statistical analysis. The data were entered and verified for errors in Microsoft Excel (v. 14.0, 2010; Microsoft Corporation). Data analysis was performed using SPSS statistical package version 18 (PASW Statistics for Windows; SPSS Inc.).

For numerical data the statistical measures were presented as the mean \pm standard deviation (minimum-maximum) and median (1st quartile-3rd quartile). For qualitative data absolute frequencies and percentages for each category from the set were used.

Standard level of significance for P-value was used and values $\leq 0.05$ were considered to reject the null hypothesis in statistical analysis. Normality of data were assessed with the Shapiro-Wilk test, the differences between normally distributed data were examined using the t-test (Student's t-test), between non-normal distributions by Mann-Whitney U test, and for categorical data the Fisher's exact test was used. The choice of t-test subtype for independent data was decided based on the result obtained using the Levene's test for comparing the variances.

\section{Results}

Demographic and myoma characteristics. The demographic data and myoma characteristics of the study patients are presented in Table I. There were no age differences between the two study groups (35.9 vs. 36.4 years old; $\mathrm{P}=0.61$ ). There was an imbalance in the proportion for area of residence; in group 1 the percentage of women from an urban area was greater than in group 2 (79.7 vs. 62.1\%; $\mathrm{P}=0.02)$. The median and the first and third quartiles for the number of myomas were similar in the two groups and no statistical difference was revealed $(\mathrm{P}=0.394)$. However, differences were obtained between the maximum size of the largest myomas, with higher values in group 1 (median 60 vs. $50 ; \mathrm{P}=0.01$ ).

Studied parameters. The studied parameters are presented in Table II. The Hb levels before LP and length of hospital stay were similar in the two study groups. $\mathrm{Hb}$ and $\mathrm{Ht}$ (as it was presumed) exhibited similar changes in our study. The values of $\mathrm{Hb}$ and $\mathrm{Ht}$ before LM were similar in both groups, with no statistically significant differences $(\mathrm{P}=0.53$ and $\mathrm{P}=0.97$, 
Table I. Demographic characteristics of the groups.

\begin{tabular}{|c|c|c|c|}
\hline Demographic characteristics & $\begin{array}{c}\text { Group } 1 \\
\text { (glypressin, } n=64)\end{array}$ & $\begin{array}{l}\text { Group } 2 \\
(n=124)\end{array}$ & $\begin{array}{c}\text { P-value (significance } \\
\text { of two tails) }\end{array}$ \\
\hline Age (years) & $35.9 \pm 5.7(23-49)$ & $36.4 \pm 5.6(23-54)$ & $0.61^{\mathrm{a}}$ \\
\hline Area of residence U/R (U\%/R \%) & $51 / 13(79.7 / 20.3)$ & $77 / 47(62.1 / 37.9)$ & $0.02^{\mathrm{b}}$ \\
\hline No. of myomas & & & $0.394^{\mathrm{c}}$ \\
\hline Median & $1(1-2)$ & $1(1-2)$ & \\
\hline Mean & $1.69 \pm 0.92(1-4)$ & $1.57 \pm 0.85(1-5)$ & \\
\hline Largest myoma (max. size in $\mathrm{mm}$ ) & $60(50-80)$ & $50(50-67.5)$ & $0.001^{\mathrm{c}}$ \\
\hline
\end{tabular}

${ }^{a}$ Independent t-test (Student's t-test) according to Levene's test for variances; ${ }^{\mathrm{b}}$ Fisher exact test for categorical data; ${ }^{\mathrm{c}} \mathrm{Mann}-\mathrm{Whitney} \mathrm{U}$ test for non-normal data.

Table II. Studied parameters.

\begin{tabular}{|c|c|c|c|c|}
\hline Studied parameters & Group 1 (glypressin) & Group 2 & Difference $(95 \% \mathrm{CI})$ & P-value \\
\hline Decrease in hemoglobin values & & & & $0.001^{\mathrm{a}}$ \\
\hline Median & $0.9(0.6-1.4)$ & $1.3(1.1-1.95)$ & & \\
\hline Mean & $1.14 \pm 0.83(-0.3-4.4)$ & $1.56 \pm 0.79(-0.9-4.5)$ & $-0.67--0.18$ & \\
\hline Hemoglobin before LM & & & & 0.53 \\
\hline Median & $13.25(12.62-13.9)$ & $13.15(12.33-13.7)$ & & \\
\hline Mean & $13.1 \pm 1.09(9.8-15.8)$ & $12.9 \pm 1.25(8.1-15.6)$ & $-0.21-0.52$ & \\
\hline Hemoglobin after LM & & & & $0.02^{\mathrm{a}}$ \\
\hline Median & $12.1(11.23-12.88)$ & $11.65(10.8-12.18)$ & & \\
\hline Mean & $11.96 \pm 1.38(8.6-14.8)$ & $11.39 \pm 1.22(7.5-13.7)$ & $0.19-0.97$ & \\
\hline Decrease in hematocrit values & & & & $0.001^{\mathrm{a}}$ \\
\hline Median & $2.2(1.53-4.33)$ & $3.7(2.52-5.67)$ & & \\
\hline Mean & $3.23 \pm 2.65(0.3-12.4)$ & $4.49 \pm 2.82(-1.2-15.5)$ & $-2.1--0.42$ & \\
\hline Hematocrit before LM & & & & 0.97 \\
\hline Median & $39.25(37.1-40.75)$ & $39.15(37.23-40.95)$ & & \\
\hline Mean & $38.83 \pm 3.22(28.4-47.4)$ & $38.67 \pm 3.58(25.9-45.2)$ & $-0.88-1.22$ & \\
\hline Hematocrit after LM & & & & $0.03^{\mathrm{a}}$ \\
\hline Median & $35.6(33-39.2)$ & $34.7(31.9-36.9)$ & & \\
\hline Mean & $35.62 \pm 4.18(25.1-45.2)$ & $34.18 \pm 3.96(22.3-41)$ & $0.2-2.65$ & \\
\hline Days of hospitalization & & & & 0.23 \\
\hline Median & $3(2-4)$ & $3(2-4)$ & & \\
\hline Mean & $3.39 \pm 1.41(2-9)$ & $3.18 \pm 1.48(1-8)$ & $-0.23-0.65$ & \\
\hline
\end{tabular}

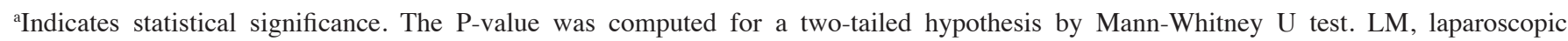
myomectomy.

respectively). Statistically significant differences were demonstrated $(\mathrm{P}<0.05)$ between the two groups, for Hb (Fig. 1) and Ht (Fig. 2), which were decreased after LM. Hb was lower in group 1 compared with group 2 (medians 0.9 and 1.3, respectively) and also the $\mathrm{Hb}$ after $\mathrm{LM}$ was higher in group 1 $(\mathrm{P}=0.02)$. Similarly, differences in $\mathrm{Ht}$ were also revealed; group 1 (median=2.2) was lower than group 2 (median=3.7) with a $\mathrm{P}=0.001$ and $\mathrm{Ht}$ after LM was also higher in group 1 $(\mathrm{P}=0.03)$. Because the values for hospitalization days were markedly similar, there was no statistical evidence of a possible difference.

\section{Discussion}

A number of researchers have reported that, especially in cases with multiple myomas, myomectomies (abdominal or laparoscopic) are associated with excessive blood loss, prolonged operating time, postoperative complications, and 


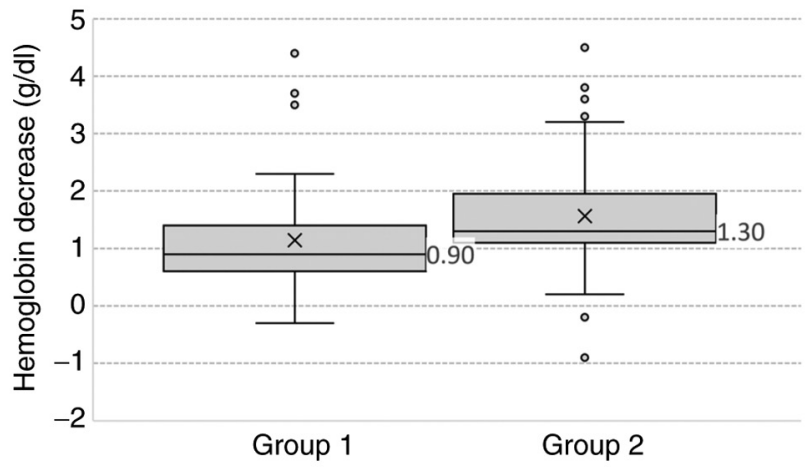

Figure 1. Box-plot chart summary distribution of hemoglobin. A decrease in hemoglobin was observed in group 1 compared to group 2. Group 1, glypressin use during laparoscopic myomectomy; Group 2, no use of an agent during laparoscopic myomectomy.

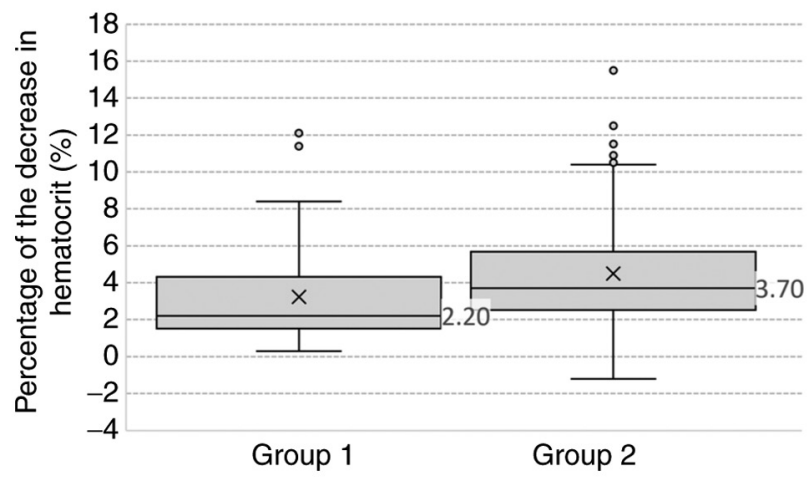

Figure 2. Box-plot chart summary distribution of hematocrit. A decrease in hematocrit was observed in group 1 compared to group 2. Group 1, glypressin use during laparoscopic myomectomy; Group 2, no use of an agent during laparoscopic myomectomy.

longer hospital stay $(20,21)$. Therefore, some physicians have created their own particular operating methods trying to decrease intraoperative blood loss (20).

LM remains a topic of serious debate. The procedure is technically difficult and involves a high risk of conversion to laparotomy. Hemorrhage is often abundant and the uterine defect can be difficult to close due to its length, location, or important bleeding. Because the conversion to open surgery is more time consuming and has higher costs than laparotomy, these risks tend to be an obstacle for the utilization of this procedure $(20,22)$.

In Europe, vasopressin is usually used as a vasoconstrictor during surgery, but in some of these countries vasopressin is not available and, thus, terlipressin (a synthetic long-acting analogue of vasopressin) is used. In Romania, a synthetic form of vasopressin, glypressin (terlipressin acetate) $0.2 \mathrm{mg} / \mathrm{ml}$ solution. Numerous studies have indicated that intramyometrial injection of vasopressin is effective in reducing blood loss during LM $(2,3,10,23,24)$.

Similar to a 2019 study by Protopapas et al, our results indicated a significantly lower blood loss in the glypressin group (10). Another large clinical trial by Frederick et al (23) compared intramyometrial injection of vasopressin vs. placebo during LM in terms of blood loss and postoperative drop in $\mathrm{Hb}$ and Ht levels (23). Their results were similar to those found in our study, namely that vasopressin was associated with a significant reduction in mean $\mathrm{Hb}$ (1.7 vs. $5.3 \mathrm{~g} / \mathrm{dl}$; P0.001) and Ht (5 vs. 13\%; P<0.001) $(10,23)$.

The safety of vasopressin has been challenged in the past due to the reports of serious and potentially lethal cardiovascular (CV) complications, including bradycardia, hypotension, arrhythmias, atrioventricular block, pulmonary edema, and even cardiac arrest $(9,10,25,26)$. In some European countries, such as France and Italy, vasopressin has been withdrawn from the pharmaceutical market in response to safety concerns.

Similar to a clinical trial by Cohen et al, no vasopressinrelated adverse events were recorded in our study (24). Srivastava et al in their randomized clinical trial revealed a reduction in blood loss during LM, revealing the superiority of vasopressin over placebo and the use of uterine tourniquet (3).

As the incidence of fibroids and childbearing age are increasing, more women are selecting LM over hysterectomy; thus, the addition of a vasoconstrictor agent may help in reducing blood loss and ease the enucleation of myomas in women undergoing LM (3).

In 2010, Walid and Heaton used pitressin (synthetic vasopressin) during surgery to decrease bleeding. Pitressin can contract the blood vessels in the myometrium, but it exhibited no effect in reducing the bleeding from the pseudocapsule vessels during LM (27).

Laparoscopic uterine artery ligation is helpful in decreasing the bleeding during LM. However, the occlusion of these arteries may also decrease uterine blood supply, and thus, may represent a disadvantage in terms of the fertility rate of these patients (20). Therefore, the use of vasoconstrictor agents becomes extremely important and helpful in this category of patients.

In our observational study, no side effects were observed with glypressin administration in the circulatory system, as the pulse rate and blood pressure were in the same normal ranges as in the control group.

Glypressin has been demonstrated to be useful in gynecological practices not only in LM. There are few studies on terlipressin/glypressin in the literature, however Pirtea et al used glypressin after clipping the hypogastric arteries to reduce the bleeding during the laparoscopic resection of a rare case of cesarean scar ectopic pregnancy. Thus, the surgery was performed in $85 \mathrm{~min}$ with $20 \mathrm{ml}$ of blood loss (28). Through the adjuvant action of glypressin, surgical management can be improved in terms of surgery duration and blood loss.

In addition, in the Netherlands, the use of terlipressin in minimally invasive gynecological interventions has become a common practice. In 2018, Overdijk et al in a double-blind randomized trial suggested that glypressin may decrease the intravasation and gaseous embolism in hysteroscopic surgery, reducing the need for performing the intervention in two steps (29).

Although, there is sufficient published evidence concerning the vasoconstrictor action of terlipressin to support its use in gynecological surgical interventions for reducing blood loss, Ryckwaert et al (30) demonstrated its vasopressor effect when directly applied on the human uterine arteries and rat aorta (10,23,28-30). More studies with larger sample 
sizes are required to accurately evaluate other advantages, such as shorter duration of surgery and decreased need for intraoperative blood transfusion (2).

Glypressin has made it possible to perform beneficial and rapid uterine reconstruction with reduced blood loss during LM. Glypressin has been revealed to be effective in reducing blood loss during LM. In the present study the use of a dilute solution was associated with no side effects. Blood loss remains an issue in most cases operated without the aid of a vasoconstrictor agent. In addition, the use of this synthetic analogue helps preserve fertility without a negative impact on pelvic blood supply. The addition of intramyometrial glypressin resulted in a significant reduction in blood loss and in the postoperative drop in $\mathrm{Hb}$ and $\mathrm{Ht}$. The combination also improved the ease of fibroid enucleation and myometrial reconstruction.

Due to the encouraging results obtained after the intraoperative administration of glypressin in the management of uterine leiomyomas, and because the literature on this topic is scarce, adequate clinical trials on glypressin use in gynecological hemorrhagic conditions are strongly recommended.

\section{Acknowledgements}

Not applicable.

\section{Funding}

No funding was received.

\section{Availability of data and materials}

The datasets used and/or analyzed during this study are available from the corresponding author on reasonable request.

\section{Authors' contributions}

DRM, AU, LH and ID contributed to the conception of the study, data interpretation and wrote the manuscript. DR, BT and VLB contributed to data collection and performed the statistical analysis. DRM and ID revised the manuscript for important intellectual content. All authors read and approved the final version of the manuscript.

\section{Ethics approval and consent to participate}

Ethical approval was obtained from the Ethics Committee of 'Cuza Voda' Obstetrics and Gynecology Clinical Hospital (Iasi, Romania) and written informed consent was obtained from all participants.

\section{Patient consent for publication}

Not applicable.

\section{Competing interests}

The authors declare that they have no competing interests.

\section{References}

1. Zhang R, Shi H, Ren F and Yuan Z: Assessment of carboprost tromethamine for reducing hemorrhage in laparoscopic intramural myomectomy. Exp Ther Med 10: 1171-1174, 2015.

2. Kongnyuy EJ and Wiysonge CS: Interventions to reduce haemorrhage during myomectomy for fibroids. Cochrane Database Syst Rev 8: CD005355, 2014.

3. Srivastava S, Mahey R, Kachhawa G, Bhatla N, Upadhyay AD and Kriplani A: Comparison of intramyometrial vasopressin plus rectal misoprostol with intramyometrial vasopressin alone to decrease blood loss during laparoscopic myomectomy: Randomized clinical trial. Eur J Obstet Gynecol Reprod Biol 228: 279-283, 2018

4. Baird DD, Dunson DB, Hill MC, Cousins D and Schectman JM: High cumulative incidence of uterine leiomyoma in black and white women: Ultrasound evidence. Am J Obstet Gynecol 188: 100-107, 2003.

5. Seracchioli R, Rossi S, Govoni F, Rossi E, Venturoli S, Bulletti and Flamigni C: Fertility and obstetric outcome after laparoscopic myomectomy of large myomata: A randomized comparison with abdominal myomectomy. Hum Reprod 15: 2663-2668, 2000.

6. Rovio PH and Heinonen PK: Transvaginal myomectomy with screw traction by colpotomy. Arch Gynecol Obstet 273: 211-215, 2006.

7. Fukuda M, Tanaka T, Kamada M, Hayashi A, Yamashita Y, Terai Y and Ohmichi M: Comparison of the perinatal outcomes after laparoscopic myomectomy versus abdominal myomectomy. Gynecol Obstet Invest 76: 203-208, 2013.

8. Soto E, Flyckt R and Falcone T: Endoscopic management of uterine fibroids: An update. Minerva Ginecol 64: 507-520, 2012.

9. Butala BP, Shah VR, Parikh BK, Jayaprakash J and Kalo J: Bradycardia and severe vasospasm caused by intramyometrial injection of vasopressin during myomectomy. Saudi J Anaesth 8: 396-398, 2014.

10. Protopapas A, Giannoulis G, Chatzipapas I, Athanasiou S, Grigoriadis T, Kathopoulis N, Vlachos DE, Zaharakis D and Loutradis D: Vasopressin during laparoscopic myomectomy: Does it really extend its limits? J Minim Invasive Gynecol 26: 441-449, 2019.

11. Koh MB and Hunt BJ: The management of perioperative bleeding. Blood Rev 17: 179-185, 2003.

12. Trehan N: Laparoscopic myomectomy: Methods to control bleeding. J Gynecol Endosc Surg 2: 33-35, 2011.

13. Wang CJ, Lee CL, Yuen LT, Kay N, Han CM and Soong YK: Oxytocin infusion in laparoscopic myomectomy may decrease operative blood loss. J Minim Invasive Gynecol 14: 184-188, 2007.

14. Shimanuki H, Takeuchi H, Kitade M, Kikuchi I, Kumakiri J and Kinoshita K: The effect of vasopressin on local and general circulation during laparoscopic surgery. J Minim Invasive Gynecol 13: 190-194, 2006.

15. Bhave Chittawar P, Franik S, Pouwer AW and Farquhar C: Minimally invasive surgical techniques versus open myomectomy for uterine fibroids. Cochrane Database Syst Rev 10: CD004638, 2014.

16. Dubuisson JB, Chapron C, Fauconnier A and Babaki-Fard K: Laparoscopic myomectomy fertility results. Ann N Y Acad Sci 943: 269-275, 2001.

17. Buckley VA, Nesbitt-Hawes EM, Atkinson P, Won HR, Deans R, Burton A, Lyons SD and Abbott JA: Laparoscopic myomectomy: Clinical outcomes and comparative evidence. J Minim Invasive Gynecol 22: 11-25, 2015.

18. Kimura T, Kusui C, Matsumura Y, Ogita K, Isaka S, Nakajima A, Ohashi K, Koyama M, Azuma C and Murata Y: Effectiveness of hormonal tourniquet by vasopressin during myomectomy through vasopressin V1a receptor ubiquitously expressed in myometrium. Gynecol Obstet Invest 54: 125-131, 2002.

19. Dubuisson J, Fauconnier A and Chapron C: Laparoscopic myomectomy. In: Atlas of Operative Laparoscopy and Hysteroscopy. 2nd edition. Donnez J and Nisolle M (eds). The Parthenon Publishing Group, New York, NY, pp215-224, 2001.

20. Zhao F, Jiao Y, Guo Z, Hou R and Wang M: Evaluation of loop ligation of larger myoma pseudocapsule combined with vasopressin on laparoscopic myomectomy. Fertil Steril 95: 762-766, 2011.

21. Liu WM, Tzeng CR, Yi-Jen C and Wang PH: Combining the uterine depletion procedure and myomectomy may be useful for treating symptomatic fibroids. Fertil Steril 82: 205-210, 2004. 
22. Dubuisson JB, Fauconnier A, Fourchotte V, Babaki-Fard K, Coste J and Chapron C: Laparoscopic myomectomy: Predicting the risk of conversion to an open procedure. Hum Reprod 16: 1726-1731, 2001

23. Frederick J, Fletcher H, Simeon D, Mullings A and Hardie M: Intramyometrial vasopressin as a haemostatic agent during myomectomy. Br J Obstet Gynaecol 101: 435-437, 1994.

24. Cohen SL, Senapati S, Gargiulo AR, Srouji SS, Tu FF, Solnik J, Hur HC, Vitonis A, Jonsdottir GM, Wang KC and Einarsson JI: Dilute versus concentrated vasopressin administration during laparoscopic myomectomy: A randomised controlled trial. BJOG 124: 262-268, 2017.

25. Riess ML, Ulrichs JG, Pagel PS and Woehlck HJ: Case report: Severe vasospasm mimics hypotension after high-dose intrauterine vasopressin. Anesth Analg 113: 1103-1105, 2011.

26. Hobo R, Netsu S, Koyasu Y and Tsutsumi O: Bradycardia and cardiac arrest caused by intramyometrial injection of vasopressin during a laparoscopically assisted myomectomy. Obstet Gynecol 113: 484-486, 2009

27. Walid MS and Heaton RL: Laparoscopic myomectomy: An intent-to-treat study. Arch Gynecol Obstet 281: 645-649, 2010
28. Pirtea L, Balint O, Secosan C, Grigoras D and Ilina R: Laparoscopic resection of caesarian scar ectopic pregnancy after unsuccessful systemic methotrexate treatment. J Minim Invasive Gynecol 26: 399-400, 2019.

29. Overdijk LE, Rademaker BMP, van Kesteren PJM, de Haan P, Riezebos RK and Haude OCH: The HYSTER study: The effect of intracervically administered terlipressin versus placebo on the number of gaseous emboli and fluid intravasation during hysteroscopic surgery: Study protocol for a randomized controlled clinical trial. Trials 19: 107, 2018.

30. Ryckwaert F, Virsolvy A, Fort A, Murat B, Richard S, Guillon G and Colson PH: Terlipressin, a provasopressin drug exhibits direct vasoconstrictor properties: Consequences on heart perfusion and performance. Crit Care Med 37: 876-881, 2009.

This work is licensed under a Creative Commons Attribution-NonCommercial-NoDerivatives 4.0 International (CC BY-NC-ND 4.0) License. 